\title{
INCLUSÃO DIGITAL E EDUCAÇÃO: POSSIBILIDADES E DESAFIOS PARA TECNOLOGIA DA INFORMAÇÃO NA ESCOLA
}

\author{
Fernanda Laleska da Silva Fernandes \\ Hedgard Rodrigues da Silva
}

\begin{abstract}
RESUMO
Este projeto procura discutir as problemáticas em relação a inclusão digital nas escolas públicas, uma vez que essa nova prática pedagógica vem sendo inserida cada vez mais rápida nas escolas, visando também apontar os pontos críticos dessa inclusão e identificando possibilidades de superação instrumental oriundos dessa informatização na escola. Propiciando uma abertura para a vivência plena da cultura digital na educação como ferramenta que venha auxiliar no processo de ensino-aprendizagem. A pesquisa procura contribuir com a reflexão sobre a formação docente a partir do Programa Nacional de Informática na Educação - PROINFO. Contudo, além de estar presente nos documentos oficiais, ainda está distante das práticas pedagógicas, uma vez que não modificou a percepção de que inclusão digital está em uma dimensão e a educação em outra. Vale ressaltar que o método de pesquisa é bibliográfico visando desenvolver a reflexão crítica, construtiva e qualitativa a respeito do tema.
\end{abstract}

Palavras chaves: Tecnologia, Educação, PROINFO.

\section{DIGITAL INCLUSION AND EDUCATION : OPPORTUNITIES AND CHALLENGES FOR INFORMATION TECHNOLOGY IN SCHOOL ABSTRACT}

This project seeks to discuss the issues regarding digital inclusion in public schools, since this new pedagogical practice has been inserted increasingly rapid in schools, aiming also to point out the critical points of this inclusion and identifying possibilities of instrumental overcoming coming this computerization in school. Providing an opening for the full experience of digital culture in education as a tool which will assist in the teaching-learning process. The research aims to contribute to the reflection on teacher training from the National Programme for IT in Education - PROINFO. However, besides being present in official documents, it is still far from pedagogical practices, since did not change the perception that digital inclusion is a dimension and education in another. It is noteworthy that the research method is literature in order to develop the critical, constructive and qualitative reflection on the subject.

Keywords: Technology, Education, PROINFO .

\section{INTRODUÇÃO}

Na contemporaneidade o mundo passa por constantes mudanças, essas mudanças se devem aos avanços científicos e tecnológicos que estão correlacionadas com as 
transformações sociais e econômicas que propiciaram transformações na forma da nossa comunicação, cada indivíduo pode compartilhar conhecimentos com um número surpreendente de pessoas espalhadas pelo mundo, diminuindo assim, a distância entre as fronteiras. Sabemos que a educação também sofreu grandes influências dessa globalização, sendo assim, viu-se a necessidade de modernizar a metodologia tradicional utilizada em sala de aula pelos professores, já que os mesmos sentem-se desafiados pelos alunos que vivem interconectados com as tecnologias que invadem as salas de aula e atrai a maioria das pessoas. (BAHIENSE, MOURA \& SILVA, 2011).

Nesta perspectiva, visando suprir as necessidades das escolas públicas em se adequarem, o governo brasileiro criou políticas públicas visando à inclusão digital de todo alunado e docentes para as novas práticas pedagógicas, capacitando os professores para o uso de materiais didáticos digitais como computadores, notebook e tabletes, propiciando assim novos saberes, com todas essas modificações repentinas devemos nos perguntar por parte dos professores, houve aproveitamento dessas tecnologias em sala de aula para a prática ensino aprendizagem e como se dá a utilização dessas ferramentas?

Nesta perspectiva, para que os professores saiam da sua zona de conforto em que sua metodologia tradicional perdura ao longo de anos de sala de aula, essa inserção na era digital requer uma orientação no qual os mesmos passam por um processo em que devem está aberto para as mudanças. Buscando incentivar essa adaptação o governo lançou o Programa Nacional de Tecnologia Educacional (PROINFO) que é um programa educacional criado pela portaria $\mathrm{N}^{\circ}$ 522/MEC de 09 de abril de 1997 para promover o uso pedagógico das Tecnologias de Informática e Comunicações (TIC) na rede pública do ensino fundamental e médio, visto que a preocupação do uso dessas práticas só se intensificou no ano de 2007 (BRASIL, 2012).

Diante disso, o professor no processo de formação continuada passa a construir conhecimento de como integrar essas novas tecnologias em suas práticas pedagógicas, superando as dificuldades tanto pedagógicas como administrativas. Esse processo tem o objetivo de propiciar aos professores novas condições de domínio às tecnologias, permitindo conhecer, como intervir na produção de conhecimento de cada aluno, sendo a experiência vivenciada base da construção. Sendo assim, os alunos devem ser estimulados e faz-se necessário esse planejamento educacional aliando educação e tecnologia de forma inovadora, motivacional, interdisciplinar e multicultural (MERCADO, 2002). 
De acordo com o site oficial do Ministério da Educação foram disponibilizados tabletes e infraestrutura adequada com banda larga sem fio além da capacitação dos professores objetivando uma socialização do uso tecnológico de comunicação e informação para inclusão digital nas escolas (BRASIL, 2012). A partir desse pressuposto, buscou-se compreender como essas inovações ajudam no desempenho do alunado bem como a perspectiva dos docentes diante dessa nova proposta educacional.

Neste caso, as políticas públicas vêm com o intuito de fazer com que as escolas tenham um bom desempenho, onde o mesmo favorece o livre acesso as novas áreas com o intuito de reduzir o analfabetismo digital tanto por parte dos professores quanto por partes dos alunos que não tem acesso por carência financeira (MORAES, LAURINO \& MACHADO, 2013).

Neste olhar, os professores saem de seu ensino tradicional para um ensino mais moderno, fazendo com que os jovens tenham novos sentidos como na percepção em si mesma, nas relações com os outros e nas valorizações pessoais e dos colegas, assim, os jovens terão um conhecimento maior para com o mundo globalizado atual. Assim com este acesso, os alunos poderão difundir de novos conhecimentos tecnológicos, ajudando em seu desempenho acadêmico, contribuindo em suas tarefas cotidianas, propiciando também, a inserção nas vastas áreas de trabalho (BRITO, 2005).

Objetivando essa nova prática pedagógica digital, além da inclusão dos alunos e formação dos professores, nesse processo de ensino-aprendizagem, o governo federal implantou na Escola Estadual de Ensino Fundamental e Médio Monsenhor Morais no ano de 2013, o Programa Nacional de Tecnologia Educacional (PROINFO) que será elemento importante neste trabalho, pois objetivamos verificar as principais contribuições da tecnologia na educação e responder a respectiva pergunta: Como os professores percebem essa nova prática pedagógica na escola pública?

O presente artigo apresenta breve discussão das primeiras análises e revisões teóricas.

O estudo tem caráter qualitativo e descritivo, buscando colher informações sobre a inclusão das tecnologias para o desenvolvimento da educação na escola publica e nos diversos âmbitos de atuação e proporcionar uma reflexão acerca da inserção da tecnologia na educação. A análise será feita, procurando a homogeneidade nas informações encontradas no material bibliográfico, visando encontrar respostas para a pergunta introdutória. 
Nesse sentido, a metodologia é pesquisa bibliográfica, acessando materiais como artigos de revistas e livros que falam sobre a Tecnologia de Informação na escola.

\section{Referencial Teórico}

Sabemos da constante preocupação por parte dos educadores com a complexidade desse processo de aprendizagem e desenvolvimento do ser humano, principalmente no âmbito educacional. Existem maneiras diferentes de se conceber o desenvolvimento e a aprendizagem, pois existem fatores intrínsecos e extrínsecos, provenientes de cada indivíduo (PALAGANA, 2001).

A partir das novas práticas pedagógicas, na qual se insere as tecnologias na educação, definimos as contribuições da abordagem construtivista, tendo como maior influência Jean Peaget, porém essa ideia de construir o conhecimento está também presente nas obras de Vygotsky, Wallon, Paulo Freire e outros. O construtivismo remete-se a construção das estruturas cognitivas do individuo durante a sua vivência (CASTAÑON, 2005). Nesta perspectiva, o construtivismo na educação é tido como uma prática pedagógica, pois atualmente essa abordagem é a mais usada para nortear o desenvolvimento de metodologias informatizadas, apresentando propostas educacionais e visando abranger as novas tecnologias de forma tanto explícita como implícita (REZENDE, 2000).

O construtivismo remete-se a construção, onde o planejamento de uma metodologia informatizada consista em criar ambientes para a aprendizagem, proporcionando uma construção e envolvimento do aluno em desempenhar uma determinada atividade, onde os professores irão apresentar ferramentas para que o aluno seja capaz de construir sua aprendizagem, no lugar de apresentar um conhecimento pronto, o aluno por sua vez através das novas tecnologias deve construir suas próprias informações, responsabilizando-se por elas.

Nesta abordagem o professor passa a criar ambientes para a aprendizagem dos alunos fazendo com que eles obtenham as informações ao invés de apenas introduzir o conhecimento, nesse sentido é importante que o professor seja inovador, estimulante, sensível, motivando o interesse dos alunos, modificando a realidade de antes na qual o professor era o único que possuía o conhecimento, de maneira a favorecer mais a relação professor-aluno.

\footnotetext{
RPI Revista de Pesquisa Interdisciplinar, Cajazeiras, v. 1, Ed. Especial, 307 - 313, set/dez. de 2016.
} 
Sendo assim o foco do construtivismo é o de facilitar o processo de construção da aprendizagem através das experiências do aluno, onde exige a flexibilidade do professor para esse processo, pois não existe uma fórmula pronta para colocar em ação as novas tecnologias introduzidas tanto nas escolas como na sociedade.

Neste sentido vale salientar que a Tecnologia de Informação e Comunicação (TIC), abrange a obtenção, o armazenamento e o processamento, para que haja uma distribuição por meio dos dados eletrônicos da informação, sendo assim considerando a tecnologia como uma fonte de conhecimento, de interação, de entretenimento, como um meio de criação e nos adequando a cultura, tornando notável a participação da sociedade na tecnologia, e com essa participação tem-se a possibilidade do individuo adquirir opiniões críticas através de suas experiências para um crescimento social, humano, cultural e educacional (BAHIENSE; MOURA; SILVA, 2011).

Nesta perspectiva a tecnologia mudou a nossa maneira de receber as informações que circulam no mundo, antes essas informações era restrita à escola e atualmente isso se modificou o que gerou um desafio para as escolas que devem fazer com que o aluno receba essas informações e com responsabilidade possam torná-las em conhecimento, ressaltando que os professores também devem estar envolvidos nessa "era digital" que está invadindo o ensino nas escolas.

A tecnologia pode influenciar na qualidade da formação de cada indivíduo em seus diferentes âmbitos de atuação, pois segundo Lima (2008), ela pode influenciar dando ênfase na aprendizagem e comunicação com os outros, buscando com que evite violência, uma má educação, buscando assim um interesse com mais aprendizagem. E ainda segundo Santarosa (2012), ela influencia com a prática de buscar superar a carência do ambiente de aprendizagem, fazendo com que esta busca possa ser considerada acessível aos mais amplos conjunto de atuação. Segundo Buzato (2008), através da capacidade de tomar para si, de assimilar ampliando um pouco mais de compreensão e transformação, estabelecendo qualquer uso de objeto tecnológico, envolvendo adaptação e reinvenção de significados.

Vale ressaltar que existem dificuldades com relação a esta nova tecnologia, pois de acordo com Lima (2008), existem as dificuldades das políticas públicas, a falta de prática, estrutura socioeconômica. Segundo Santarosa (2012), a falta de habilidade para o uso destas novas tecnologias, falta de conhecimento tecnológico e falta de capacitação. Buzato (2008) nos diz que há falta de materiais didáticos tecnológicos, tempo e disposição pra um novo 
aprendizado. De acordo com Andrade (2007), Os profissionais enfrentam dificuldades porque aqueles que não compartilham da inclusão digital, ou não tem acesso à mesma podem ficar excluídos. Algumas dificuldades apontadas também são em relação à questão do local geograficamente falando que às vezes fica longe dos principais canais de informação, dificultando o acesso ao conhecimento e a informação especializada.

Segundo Moraes (2013), é notório que as dificuldades estão relacionadas ao acesso desigual de informação e internet entre os segmentos representados nos conselhos de saúde, e também na questão da localidade que nem sempre têm o acesso à tecnologia, pode-se citar também a falta de compreensão na linguagem muito técnica dessas tecnologias. De acordo com Silva (2005), as dificuldades enfrentadas referem-se à questão de que essas tecnologias não estão ao alcance de todos, pois nem todos tem essa oportunidade.

De acordo com Frezza, Maraschin e Santos (2009), as dificuldades encontradas são as problemáticas da exclusão das pessoas de nível social baixo e em vulnerabilidade, visto que é fundamental a inserção dos mesmos para criar estratégias que permitem dar visibilidade a outras e diferentes formas de pensar, agir e sentir. Neste sentido para Silva (2005), a inserção das tecnologias de informação e comunicação na escola está ligada ao projeto políticopedagógico visando uma melhoria no processo de ensino aprendizagem, capacitando assim, os docentes para que possam preparar os jovens para o mercado de trabalho, aumentando também, a produção e o consumo desses recursos.

\section{Conclusão}

No âmbito geral, este trabalho foi de grande importância para a formação de qualidade do profissional da educação, dando maior autonomia de conhecimento em relação à percepção dos professores sobre o uso das tecnologias em seus variados âmbitos para que possam lidar com as necessidades de cada um, desta maneira, partindo de uma perspectiva positiva, foi avaliado que a partir dos resultados obtidos corroborou-se que houve mudanças de atitudes em relação ao que se pensavam a respeito do manuseio das novas ferramentas para o âmbito da educação, vale salientar as dificuldades enfrentadas pelas políticas públicas, percebeu-se que tanto contribui como dificulta a falta de preparação dos profissionais para a orientação dos alunos e para lidar com essa nova realidade.

RPI Revista de Pesquisa Interdisciplinar, Cajazeiras, v. 1, Ed. Especial, 307 - 313, set/dez. de 2016. 


\section{REFERÊNCIAS}

ANDRADE, A. C. R. Processo de inclusão digital em rede empresarial do segmento de suprimentos industriais: utilização de tecnologias de informação e comunicação. vol.35, no.1, p.7-15, 2007.

BAHIENSE, V. A.; MOURA, M.A.; SILVA, E. F. Tecnologias, Códigos e Linguagens Aplicados à Educação. Editora Faibra: Terezina, 2011.

BRASIL. (2012). Ministério da Educação. Acedido em 03 de Setembro de 2016 em:http://portal.mec.gov.br/index.php?option=com_content\&view=article\&id=236\&Itemid= $\underline{471}$.

BRITO, A. J. R. Consórcio social da juventude de São Paulo tecendo considerações sobre as escolas e as perspectivas de inserção no mundo do trabalho das juventudes. Imaginário v. 11, $\mathrm{n}^{\circ}$ 11, São Paulo - DEZ, 2005.

BUZATO, M.E.K. Cultura digital e apropriação ascendente: apontamentos para uma educação 2.0. Educação em Revista, vol.26, no.3, Belo Horizonte, 2010.

CASTANÕN, G. A. Ciências e cognições. Revista Interdisciplinar de estudos da cognição Vol. 05, 2005.

FREZZA, M.; MARASCHIN, C.; SANTOS, N. S. Juventude como problema de política publica. Psicologia \& Sociedade V.21, N. 3, 2009.

LIMA, D. G.; Furtado, v. Política pública dos telecentros e prevenção da violência. Revista Sociologias, $\mathrm{n}^{\circ}$ 20, Porto Alegre, 2008.

MERCADO, L. P. L. Novas tecnologias na educação [recurso eletrônico]: reflexões sobre a prática. Dados eletrônicos. Maceió. Edufal, 2002.

MORAIS, M. C.; LAURINO, D. P.; MACHADO, C. C. Práticas docentes atualizadas na ecologia digital. Revista Renole novas tecnologias na educação. V.11. N.3, 2013.

PALAGANA, I. C. Desenvolvimento em Piaget e Vygotsky a relevância do social, 3. Ed. São Paulo, Summus, 2001.

REZENDE, F. As novas tecnologias na pratica pedagógica sob a perspectiva construtivista. Vol. 02 n. 1 p. 1-18, 2000.

SANTAROSA.L.M.C.; CONFORTO,D.; Basso,L.O. Eduquito: ferramentas de Autoria e de colaboração acessíveis na perspectivada web 2.0. Revista Bras - Ed esp, Rio de Janeiro, 2012.

SILVA, H. et al. Inclusão digital e educação para a competência informacional: uma questão de ética e cidadania. vol.34, no.1, Brasilia, 2005.

RPI Revista de Pesquisa Interdisciplinar, Cajazeiras, v. 1, Ed. Especial, 307 - 313, set/dez. de 2016. 